\title{
Research on the Hybrid Teaching Mode Based on SPOC in the Teaching of Analog Electronic Technology
}

\author{
Panfeng Guo \\ School of Electrical and Energy \\ China Three Gorges University \\ Yichang, China \\ 296472604@qq.com
}

\author{
Shiwei Su \\ School of Electrical and Energy \\ China Three Gorges University \\ Yichang, China \\ 21864436@qq.com
}

\author{
$\mathrm{Xin} \mathrm{Li}^{*}$ \\ School of Electrical and Energy \\ China Three Gorges University \\ Yichang, China \\ 397038289@qq.com
}

\begin{abstract}
Based on the background of SPOC, this paper introduces a hybrid teaching mode that combines offline teaching, traditional teaching and online teaching, and flipped classroom. This paper takes the analog electronic technology course as an example. To discuss SPOC based hybrid teaching mode based on flipped classroom Firstly, the teaching content is recombined and classified, then how to design the hybrid teaching is introduced, and finally the curriculum assessment under the mixed teaching mode is re-identified. According to the above research, the hybrid teaching mode is used to solve the disadvantages of the traditional teaching mode, and the necessity of hybrid teaching mode can be concluded by students' scores At the end of the paper, the problems of the hybrid teaching mode in the basic teaching of analog electronic technology are described, and countermeasures are taken to make the future teaching mode more targeted and efficient.
\end{abstract}

Keywords-SPOC, flipped classroom, hybrid teaching, teaching mode

\section{INTRODUCTION}

With the advent of the Internet age, teaching methods are constantly being updated and reformed to meet the needs. A few years ago, new words such as MOOC (massive open online courses), SPOC (Small Private Online Course), and flipped classroom appeared one after another[1]. This has made the reform of teaching embark on a path of rapid change, and the pattern of talent cultivation has also increased and changed. Therefore, traditional university classroom teaching of "infusing type" can no longer meet the needs of implanting knowledge in the information age, and both teachers' teaching and students' learning should be student-centered. so, it is inevitable for higher education to develop online. In addition, taking the author's college as an example, in the context of this foundation and engineering professional certification, the college also made a student-centered teaching reform. Establish

Project: Teaching and research project of China Three Gorges University. Item no. J2018011 online open online classrooms, purchase online learning video resources, etc. to achieve SPOC-based hybrid teaching. The analog electronic technology course is a basic course for a relatively theoretically advanced electrical and electronic major. The quality of learning may have a certain impact on the learning and design of follow-up professional courses. At present, the traditional classroom teaching has the following problems: First, there are fewer hours of study, but there are many contents, how to enable students to acquire knowledge in a comprehensive and high quality is the main goal of the classroom; Secondly, in traditional indoctrinated classrooms, students have low participation and less interaction, and it is difficult to achieve better effects; In addition, the traditional teaching mode is mainly based on theory, and the practice of electronic technology courses in subsequent use is more, and it is necessary for students to properly master the application of software. Based on this, this paper will discuss the application of the hybrid teaching mode based on SPOC and flipped class in the teaching of analog electronic technology.

\section{THE Hybrid TEACHING Mode BASED ON SPOC}

SPOC (Small Private Online Course) is a small-scale restrictive online course, in which Small and Private are relative to Massive and Open in MOOC, and Small refers to students ranging in size from dozens to hundreds of people. This is more suitable for the reform of the teaching model of ordinary colleges and universities.[2]

The current SPOC teaching case in our school is mainly for college students. It is a mixed learning mode that combines classroom teaching and online teaching. It is a college campus classroom that uses MOOC lecture videos (or both online evaluation functions) to implement flipped class teaching. The basic process is that the teacher arranges these video materials on the SPOC website as homework, and sometimes releases the content previewed in advance through the Rain Classroom. 
Then answer the student's questions in the classroom, find out what knowledge the students have absorbed, and which ones have not been absorbed, and work with the students to complete assignments or other tasks in class. In general, teachers can freely set and control the progress, rhythm and scoring system of the course according to their own preferences and the needs of students, thus achieving a hybrid of online and offline teaching modes.

\section{DESIGN OF HYBRID TEACHING MODE BASED ON FLIPPED CLASS}

Flipped classroom, the literal meaning is to flip the traditional classroom so that students become active instead of passive. Contrary to traditional classroom teaching, it puts the process of information transfer outside the classroom. The teaching materials are mainly provided by SPOC, and the students complete the course learning. This type of learning can enhance students' initiative, enthusiasm and creativity. However, for "analog electronic technology", it is not appropriate to completely copy the foreign flipped classroom teaching mode. Some of the knowledge points of this course are abstract and complex, which determines that not all course content is suitable for flipped classroom. For example, the principle of FET and composite amplifier circuit. At this time, traditional classroom teaching is needed to solve such knowledge points. Therefore, different teaching methods can be adopted for different course contents, and the teaching content needs to be reconstructed, and the evaluation method is newly identified. In addition, the SPOC-based flipped classroom is called online teaching, and the traditional teaching method is called offline teaching[3]. A block diagram of the hybrid teaching mode is shown in Fig. 1 below.

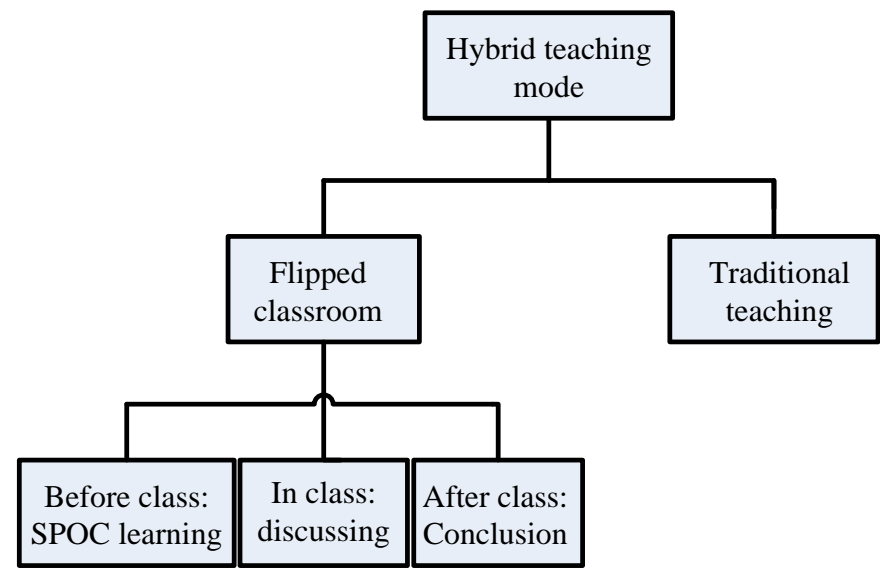

Fig. 1. Block diagram of hybrid teaching mode

\section{A. Recombination of content}

Before the start of the analog electronic technology, the content of the course needs to be newly classified into two parts: "tripe" and "not tripe". According to the characteristics of the content, traditional classrooms are still used for content that is not suitable for students' self-study. For content that is relatively independent and analogous, a " flipped classroom " can be used. In the initial implementation of the reform, try to select content that is less content and easy to understand as " tripe ". The specific combinations are shown in Table 1 below. (On the next page)

\section{B. The specific implementation process of the hybrid teaching mode}

The hybrid teaching mode puts forward higher requirements on students' self-study and understanding. Three steps are set in this process: study preview, discuss in class, leak filled with the help of teachers[4]. Firstly, students will randomly be assigned before class, the group count depends on the number of tripe content, the number of students in group is about 6.for teaching content that need to flip, students will learn in online video though SPOC and complete the corresponding online tests. The group which is required to explain in class need to make corresponding PPT file, it can complete under the guidance of teachers. Secondly, select one group randomly and arrange them to explain in class. Other groups can ask questions after the explanation, all the members in group which explain in class before can answer the questions. Then teacher will summarize the teaching content and leak filled in remaining time. Last, students are required to finish the test subject in SPOC and summarize the main content after every flipped classroom. Of course, after class is another begin of next class, teachers can release the content that students need to preview before next class though internet.

As shown in table 1, one of them is taken as an example to illustrate the hybrid teaching mode based on flipped classroom. For example, section 5.5 of chapter 5 is the analysis of common collector amplifier circuit, and section 5.6 is the analysis of common base amplifier circuit. These two sections are more suitable for flipped classroom. Because students have learned the analysis process of common emitter amplifier circuit in the previous chapters, and its analysis principle is basically the same, so, students can use SPOC resources and books to learn by themselves. Teachers can answer questions and solve puzzles in class, and implement flipped classroom.

\section{Course assessment and evaluation method}

Compared with traditional teaching model, the hybrid teaching model based on flipped classroom is convincing and objective for the evaluation of students' learning process and learning ability. For the assessment of students' academic performance, the traditional assessment method only relies on the results of the final examination paper and ignoring the assessment of the learning process and the assessment of practical ability[5]. Discussion and communication in flipped classroom can reflect students' participation in class and sense of teamwork. Students' learning behavior can be reflected by SPOC online learning time. The system automatically records the learning time, and teachers can know about students' independent learning through systematic statistics at any time, so as to make an objective evaluation of students' learning attitude. Online tests record how well students have completed their assignments. Under the traditional teaching method, students' grades depend on the score of examination. while under the hybrid teaching model, students' achievement distribution should be diversified and emphasize processes. 
The score distribution of Analog Electronics course is shown in Fig. 2.

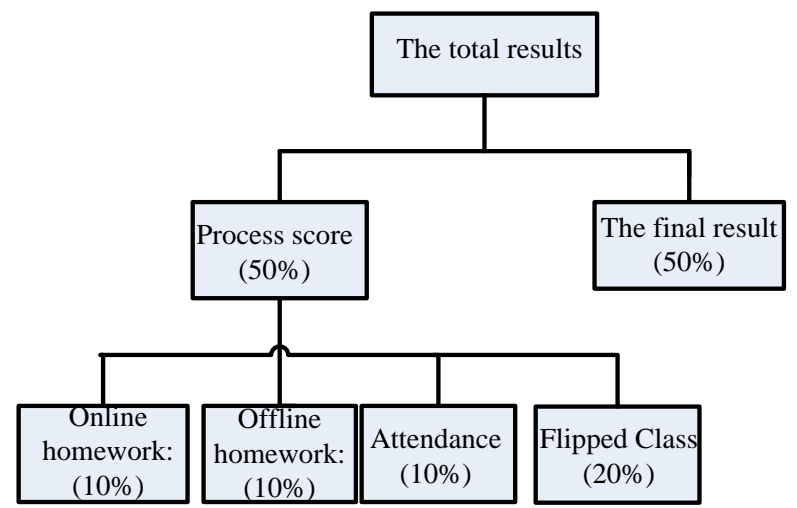

Fig. 2. Block diagram of results

TABLE I. CLASSIFICATION OF ANALOG ELECTRONIC TECHNOLOGY COURSE CONTENT

\begin{tabular}{|c|c|}
\hline Main teaching content & Teaching form \\
\hline Chapter 1 Introduction & $\begin{array}{c}\text { Traditional } \\
\text { teaching }\end{array}$ \\
\hline Chapter 2 operational amplifier (flipped content Section & $\begin{array}{c}\text { Hybrid } \\
\text { Teaching }\end{array}$ \\
\hline Chapter 3 Diode and its basic circuit ( flipped content \\
Section 3.5) & $\begin{array}{c}\text { Hybrid } \\
\text { Teaching }\end{array}$ \\
\hline Chapter 4 FET and its amplifying circuit & $\begin{array}{c}\text { Traditional } \\
\text { teaching }\end{array}$ \\
\hline Chapter 5 BJT triode and its amplifying circuit ( flipped & $\begin{array}{c}\text { Hybrid } \\
\text { Teaching }\end{array}$ \\
\hline content Section 5.5 and Section 5.6) & $\begin{array}{c}\text { Traditional } \\
\text { teaching }\end{array}$ \\
\hline Chapter 6 Frequency response & $\begin{array}{c}\text { Traditional } \\
\text { teaching }\end{array}$ \\
\hline Chaptog integrated circuit & $\begin{array}{c}\text { Hybrid } \\
\text { Teaching }\end{array}$ \\
\hline Chapter 9 Power amplification circuit & $\begin{array}{c}\text { Flipped } \\
\text { classroom }\end{array}$ \\
\hline Chapter 11 DC regulated power supply & $\begin{array}{c}\text { Hybrid } \\
\text { Teaching }\end{array}$ \\
\hline Chapter 10 Signal processing and signal generation circuit & $\begin{array}{c}\text { Flipped } \\
\text { classroom }\end{array}$ \\
\hline
\end{tabular}

\section{PROBlems AND COUNTERMEASURES IN THE HYBRID TEACHING MODE}

The process of teaching reform is not simple and full of challenges. In the implementation process, the following problems exist. On the one hand, it is not good for students with poor learning motivation[6]. When grouping, only one student in each group needs to explain in class. Therefore, some students have a chance to be lucky and the preparation is poor. Response measures: Each flipped classroom is randomly grouped, and the presenter also randomly selects the presenter to report on behalf of the group. In this way, every member of the group can't slack off because it directly affects the score of all members of the group. Moreover, teachers can also randomly select content for students to speak. This requires students to integrate the knowledge they have learned and to supervise the students. In addition, it is more difficult to implement the flipped classroom in large classes. When the number of people is large, the grouping situation is relatively complicated, and the amount of content that can be flipped is relatively fixed, and the number of people in each group is too large. This does not take advantage of the assessment of each student's situation and is difficult to implement. Response measures: implement small class teaching. Or for a larger class, two teachers are assigned as supplementary teaching.

\section{CONCLUSION}

In the teaching of the course of analog electronic technology, the hybrid teaching mode is introduced, which brings about changes to classroom teaching. Based on SPOC online resources, students' learning is not restricted by time and place, which improves students' learning initiative and turns passive into active. Through group learning in flipped classroom, students' ability of teamwork is enhanced. At the same time, this kind of hybrid teaching mode also puts forward higher requirements for teachers. The teaching content should be recombined and adjusted, and the classroom teaching should be designed to adapt to the teaching reform.

\section{REFERENCES}

[1] Ma lei. Study on the learning environment design of virtual experiment teaching of electronic technology in vocational education from the perspective of CAS theory [D]. Liaoning normal university, 2006. (In Chinese)

[2] Wang Xin, Zhou mingyue, Chen geheng, Zhai shuang, Yu weibo. "Research on the hybrid teaching mode of circuit and analog electronic technology in the era of "Internet +"” [J].Journal of higher education, 2019(09):16-18+21. (In Chinese)

[3] Wei jinyan. A learner-centered study on the mixed teaching mode of "fundamentals of electronic technology" [J]. Modernization of education, 2018,5(35):258-260. (In Chinese)

[4] Yuan yang. Teaching practice of basic electrical and electronic technology based on mixed teaching mode $[\mathrm{J}]$. Science public (science education), 2018(07):113. (In Chinese)

[5] Ma xuefen. Research on mixed teaching mode based on MOOCs in the teaching of " analog electronic technology" [J]. The southern farm machinery, 2018,49(02):16-17. (In Chinese)

[6] Yang ling. Practice and research on the mixed teaching mode of electronic technology application major in vocational colleges [J]. Industry and information education, 2016(05):60-64. (In Chinese) 